Sónia Gonçalves · John Cairney · João Maroco

M. Margarida. Oliveira · Célia Miguel

\title{
Evaluation of control transcripts in real-time RT-PCR expression analysis during maritime pine embryogenesis
}

Received: 17 November 2004 / Accepted: 18 March 2005/Published online: 21 July 2005

(C) Springer-Verlag 2005

\begin{abstract}
In order to determine the suitability of reference or housekeeping genes as internal controls in real-time reverse transcriptase PCR (RT-PCR) assays for quantification of target mRNAs, we studied the levels of expression of four candidate reference genes in maritime pine by real-time RT-PCR. The expression levels obtained for glyceraldehyde-3-phosphate-dehydrogenase, 18S ribosomal RNA, eukaryotic translation initiation factor eIF4AII and ubiquitin in nine stages of embryo development revealed that none of the genes tested proved to be suitable as an internal control. Copy number quantification of the four transcripts showed an average relative variation of seven fold. We propose that the combination of a precise method for RNA quantification, internal controls for monitoring RT reaction and PCR efficiency and a robust external standard curve can guarantee a reliable absolute quantification of mRNA transcripts in real time RT-PCR. This approach may avoid the controversy in the use of housekeeping genes and may assume special significance in tissues undergoing developmental changes.
\end{abstract}

S. Gonçalves · M. Margarida. Oliveira $\cdot$ C. Miguel $(\bowtie)$ Grupo Pinus, Instituto de Biologia Experimental e Tecnológica (IBET)/Instituto de Tecnologia Química e Biológica (ITQB), Aptd. 12, 2781-901 Oeiras, Portugal

E-mail: cmiguel@itqb.unl.pt

Tel.: + 351-21-4469644

Fax: + 351-21-4421161

J. Cairney

School of Biology and Institute of Paper Science and Technology @ Georgia Tech, Georgia Institute of Technology, 500, 10th Street, Atlanta, N.W. 30332-0620, USA

J. Maroco

Grupo de Estatística e Matemática, Instituto Superior de Psicologia Aplicada, Rua Jardim do Tabaco, 34, 1149-041 Lisboa, Portugal

M. Margarida. Oliveira

Departamento de Biologia Vegetal, Faculdade

de Ciências de Lisboa, Bloco C2, Piso 1,

Campo Grande, 1749-016 Lisboa, Portugal
Keywords Housekeeping genes $\cdot$ Maritime pine $\cdot$ Plant embryogenesis $\cdot$ Real-time PCR

Abbreviations GAPDH: Glyceraldehyde-3-phosphatedehydrogenase - eIF4AII: Eukaryotic translation initiation factor 4AII - 18S rRNA: 18S ribosomal RNA - LEA: Late Embryogenesis Abundant - ABA: Abscisic acid

\section{Introduction}

Real-time RT-PCR is becoming the method of choice for an accurate measurement of transcript abundance of selected genes. The high sensitivity, accuracy and reproducibility of the technique support the numerous applications of real-time RT-PCR (Kang et al. 2000; Mackay et al. 2002; Cottrell et al. 2004; Johnson et al. 2004). When measuring RNA expression an important feature is the normalization between samples. The quantification procedure of choice depends on the target sequence, on the expected range of the mRNA amount present in the tissue, on the degree of accuracy required, and on whether quantification needs to be relative or absolute (Freeman et al. 1999). For quantitative analysis of gene expression the most commonly used method is relative quantification: the target concentration in each sample is calculated relative to another gene transcript, a housekeeping gene, and the result is expressed as a target/reference ratio. This normalization to a reference gene has the advantage of correcting qualitative and quantitative factors influencing PCR, like differences in the input RNA amount or in efficiencies of the reverse transcription reaction. A standard curve, based on serial dilutions of an external standard, is used to determine the concentration of the target and the reference gene.

The ideal internal standard should be expressed at a constant level among different tissues of an organism, at 
all stages of development, and should be unaffected by the experimental treatment (Bustin 2000). However, it is unlikely that such a gene would exist since biological systems are dynamic and constantly changing in response to their environment. Therefore, the most appropriate internal control would be one that has the least variation on its expression under various experimental conditions and in different tissues types (FerozeMerzoug et al. 2002). Glyceraldehyde-3-phosphatedehydrogenase (GAPDH) is a housekeeping gene widely used as internal standard. Because this enzyme is essential for the maintenance of cell function, it is generally assumed that it is constitutively expressed at similar levels in all cell types and tissues and many studies make use of its encoding gene as control without proper validation of its presumed stability of expression. Indeed, there have been numerous reports demonstrating that the mRNA levels of GAPDH gene are not constant, where the experimental treatment or condition influences its expression (Schmittgen and Zakrajsek 2000). The use of ribosomal RNA has been recommended as internal standards for mRNA quantification studies as the various RNA transcripts are generated by a distinct polymerase (Paule and White 2000) and their levels are less likely to vary under conditions that affect the expression of mRNAs (Barbu and Dautry 1989). The higher level of expression of rRNA comparing to the target mRNA has been pointed out as a disadvantage in its use as internal standard. Many other genes including ubiquitin and eIF4AII have also been identified as housekeeping genes in different tissues (Daram et al. 1998; Eisenberg and Levanon 2003). To ensure the credibility of the results in a set experimental design using gene controls, a previous study should be performed to determine the most suitable housekeeping genes (Giulietti et al. 2001).

There have been several reports on the study of genes as internal standards for quantitative real-time PCR in animal tissues (Goidin et al. 2001; Feroze-Merzoug et al. 2002; Lupberger et al. 2002). In plant tissues, real time RT-PCR technique is being used for quantification of gene expression (Charrier et al. 2002; Mason et al. 2002), and in the majority of studies 'housekeeping genes' are being employed as internal controls without an adequate validation of the stability of expression of these genes under the conditions assayed. In many cases genes traditionally chosen for the constancy of their expression have gained this reputation based on assays conducted under a limited number of conditions or with relatively few tissues. Recent data in humans shows considerable variation in expression of certain housekeeping genes in different tissues (Vandesompele et al. 2002; Bustin et al. 2002). A study of the expression levels of ribosomal RNA 18S, GAPDH, actin and tubulin in rice seedlings subjected to UV-irradiation revealed that only $18 \mathrm{~S}$ ribosomal RNA was a suitable internal control for real time RT-PCR (Kim et al. 2003). The difficulty in selecting an appropriate internal control for studies comparing gene expression among different developmental stages or under different environmental conditions was recently demonstrated, in mature poplar trees (Brunner et al. 2004).

Developing embryos exhibit an extraordinarily dynamic program of gene activity in the course of cell differentiation, organ formation and maturation. Given the recent data cited above, the selection of a stable reference against which fluxes in embryonic gene expression may be gauged requires a modified approach. Here we describe a method for absolute quantification of mRNA based on comparison to standard curves generated by amplification of reference plasmids. We have performed absolute quantification by real time RT-PCR of four housekeeping genes-glyceraldehyde-3-phosphate-dehydrogenase (GAPDH), 18S ribosomal RNA (18S rRNA), eukaryotic translation initiation factor eIF4AII (eIF4AII) and ubiquitin over the course of embryo development in maritime pine (Pinus pinaster). Our results show that each of these genes shows considerable fluctuation in RNA levels over the course of pine embryo development.

\section{Material and methods}

Plant material

Maritime pine (Pinus pinaster L.) immature cones were collected from clones of one open-pollinated 'plus' tree

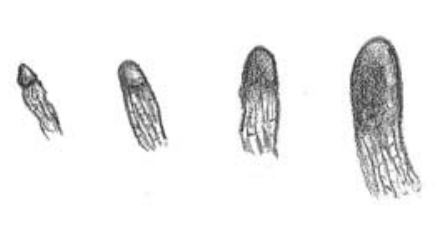

$\begin{array}{llll}\text { T0 } & \text { T1 } & \text { T2 } & \text { T3 }\end{array}$
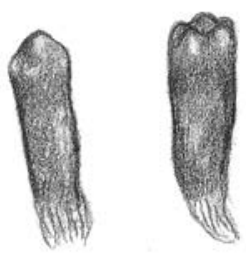

T4

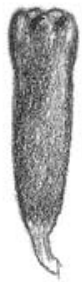

T4B T5

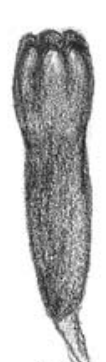

T6

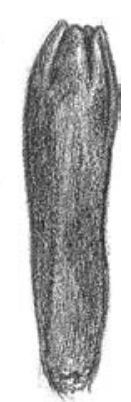

T7

Fig. 1 Stages of embryo development (T0-T7) used for gene expression analysis 
growing in a seed orchard at Mata Nacional do Escaroupim, Salvaterra de Magos, Portugal. The collection was performed weekly during the period of June 23rd to July 30th, 2002. Cones were opened and seeds were collected for isolation of embryos. The megagametophyte was opened and the dominant embryo or mass of embryos removed and evaluated for developmental stage. Nine different stages of embryo development were considered (T0, T1, T2, T3, T4, T4B, T5, T6 and T7; Fig. 1), based on the staging system of Pullman and Webb (1994). Staged zygotic embryos were then placed in a cryostorage vial partially immersed in liquid nitrogen. Twenty to 50 similar-staged embryos were collected per vial. Frozen embryos were stored at $-70^{\circ} \mathrm{C}$ until analyses were performed.

\section{RNA extraction and cDNA preparation}

Total RNA was extracted from zygotic embryos in different developmental stages using RNeasy extraction kit (Qiagen). To eliminate the residual genomic DNA present in the samples, RNA was treated with RNAsefree DNAse I (Qiagen) according to the manufacturer's instructions. Total RNA concentration was then determined with RiboGreen ${ }^{\circledR}$ RNA quantitation reagent (Molecular Probes), with the quantification performed at $480 / 520 \mathrm{~nm}$ (excitation/emission).

Two and a half micrograms of total RNA were reverse transcribed using the First Strand cDNA Synthesis Kit (AMV) (Roche, Manheim, Germany), according to the manufacturer's instructions.

\section{Oligonucleotide design}

Primers specific for the four housekeeping genes and for a LEA (Late Embryogenesis Abundant) - like gene of $P$. pinaster (Table 1), were designed using Primer Premier 5.0 (Premier Biosoft International, Palo Alto, CA, USA). Primers were designed to have a size of $18-30$ base pair (bp), GC content of $40-60 \%$ and $\mathrm{Tm}$ of $55-65^{\circ} \mathrm{C}$. Other criteria such as likelihood of primer self-annealing were also taken into account. All oligonucleotides were synthesized by TIB Molbiol Inc (Berlin, Germany). The predicted fragment sizes ranged from $130 \mathrm{bp}$ to $400 \mathrm{bp}$ (Table 1).

Amplification of ubiquitin, GAPDH, EIF4AII, 18S

rRNA and LEA-like, construction of standards

A search was performed in the databases to identify commonly referred housekeeping genes and a LEA-like gene in pine. Primers were designed as described above for the target cDNA sequences of five genes: GAPDH, 18S rRNA, eIF4AII, ubiquitin and LEA-like. Amplification of the genes was performed using cDNA synthesized using RNA from T2 (housekeeping genes) or T7 (LEA-like gene) stages of embryo development. A gradient PCR was performed in a total of $50 \mu \mathrm{l}$ containing $0.2 \mathrm{mM}$ dNTPs, $2.5 \mu \mathrm{M}$ of each primer, $2 \mathrm{U}$ of Taq DNA polymerase (Promega) in a buffer consisting of $50 \mathrm{mM} \mathrm{KCl}, 10 \mathrm{mM}$ Tris- $\mathrm{HCl}, 1.5 \mathrm{mM} \mathrm{MgCl}_{2}$ and $2.5 \mu \mathrm{l}$ of reverse transcribed total RNA. Samples were first denatured at $94^{\circ} \mathrm{C}$, for $4 \mathrm{~min}$, followed by 34 cycles of $94^{\circ} \mathrm{C}$ for $45 \mathrm{~s}, 48-54^{\circ} \mathrm{C}$ for $45 \mathrm{~s}$ and $72^{\circ} \mathrm{C}$ for $90 \mathrm{~s}$. A final extension step of $4 \mathrm{~min}$ at $72^{\circ} \mathrm{C}$ completed the program. The amplified PCR products were separated by electrophoresis in 1\% agarose gels, stained with ethidium bromide and visualized under UV light. After excision from the gel, the PCR product was purified and cloned into the pGEM-T-easy I (Promega) vector. Plasmid DNA was quantified with a fluorometer using PicoGreen RNA quantitation reagent (Molecular Probes) and the cDNA-cloned inserts were sequenced for confirmation of specific amplification.

\section{Real-time PCR}

\section{Construction of standard curves}

To determine the absolute number of specific cDNA molecules present in the samples, standard curves were created. The measurements of plasmid concentration were performed in triplicate and then converted to the molecule number as previously described (Fronhoffs et al. 2002). For each gene studied, a range of six dilutions $\left(10^{7}-10^{2}\right.$ copies) of the plasmid containing the

Table 1 Sequences of the primers used to amplify genes under study by real-time RT-PCR

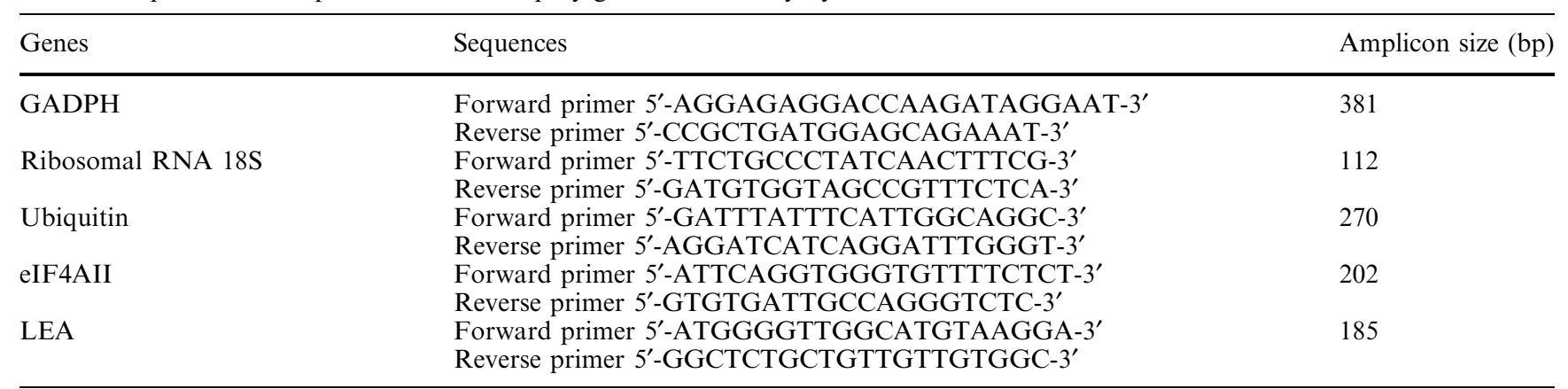


target gene (with four replicates) was tested in separate experiments under the same experimental conditions as used for amplification of the cDNA (embryo RNA). PCR was performed in a total of $20 \mu \mathrm{l}$ consisting of $1 \mathrm{mM} \mathrm{MgCl} 2,0.3 \mu \mathrm{M}$ of both PCR primers, $2 \mu \mathrm{l}$ of DNA Master SYBR Green I (Roche) and $2 \mu$ of plasmid DNA. Following $10 \mathrm{~min}$ of denaturation at $95^{\circ} \mathrm{C}$, 45 cycles were performed with $10 \mathrm{~s}$ denaturation at $95^{\circ} \mathrm{C}, 5 \mathrm{~s}$ annealing at $52 / 54 / 55 / 55 / 57^{\circ} \mathrm{C}$ (ubiquitin/18S rRNA/GAPDH/eIF4AII/LEA-like) and extension at $72^{\circ} \mathrm{C}$ for $11 / 5 / 16 / 8 / 8 \mathrm{~s}$ (ubiquitin/18S rRNA/GAPDH/ eIF4AII/LEA-like). To distinguish specific product from nonspecific products and from primer dimers, a melting curve was obtained immediately after amplification. Following a denaturation step at $95^{\circ} \mathrm{C}$ at a start temperature of $62 / 64 / 65 / 65 / 67^{\circ} \mathrm{C}$ (ubiquitin/18S rRNA/ GAPDH/eIF4AII/LEA-like) and an end temperature of $95^{\circ} \mathrm{C}$, with a temperature increase of $0.1^{\circ} \mathrm{C} / \mathrm{s}$, a melting curve was obtained. PCR and melting products were detected in real time with the LightCycler Instrument (Roche). Ten microliters of each sample were run in gel electrophoresis ( $1 \%$ agarose) and visualized after ethidium bromide staining.

\section{Sample quantification}

Reverse transcribed cDNA samples from the nine stages of embryo development were amplified by PCR using a LightCycler. The primers used for amplification are listed in Table 1. PCR conditions were the same as described for the construction of standard curves. To determine intra-run variability, all samples were run in triplicate and for the inter-run variability assessment, three independent experiments were performed, using the same RT cDNA pool.

Calculations and statistical data analysis

\section{Standard curve}

The efficiencies of amplification (Es) of ubiquitin, GAPDH, eIF4AII and 18S rRNA standard curves were calculated according to the equation: $\mathrm{Es}=10^{- \text {slope }}-1$ where the "slope" is that of the linear regression of Log (target concentration) versus $\mathrm{Ct}$ (threshold cycle, see below). Intra-run variation was determined according to the equation:

$\pm \%$ Molecules $=\left((E s+1)^{\mathrm{SD}}-1\right) \times 100 \%$,

where SD is the standard deviation of $\mathrm{Ct}$ obtained from four independent replicates per run (Rutledge and Côté 2003). The percentage of variability in the Log (gene copy number) explained by the run $\mathrm{Ct}$ was estimated by the coefficient of determination $\left(\mathrm{r}^{2}\right)$ of the linear regression of Log (copy number) versus $\mathrm{Ct}$ estimated with SPSS v. 12 (SPSS Inc., Chicago, IL, USA).

\section{Quantification}

Data in Figs. 2 and 3 are the average \pm SE of gene copy number from three replicates of three independent samples of 20-50 embryos per developmental stage. Statistical significant differences were evaluated by a one-way Analysis of variance (ANOVA) for $\alpha=0.05$, and statistically significant mean differences between developmental stages were identified with Tukey's HSD using SPSS v. 12 (SPSS Inc.). Data subjected to ANOVA and Tukey's HSD were Ln transformed to meet the requirements of normality and homogeneity of variances.

\section{Results}

\section{Generation of standard curves}

A standard curve was created for each gene in this study using a range of serial dilutions of the plasmid containing the target cDNA with four replicates. The LightCycler software analyzed the spectral data collected at the end of the extension phase of each cycle and plotted fluorescence intensity versus cycle number. The threshold cycle $(\mathrm{Ct})$, defined as the fractional cycle at which the fluorescence signal becomes significantly different from the baseline signal, was manually determined by the fit-point method provided by the software. By plotting the Cts against the logarithm of the calculated initial copy numbers, a standard curve was generated by the LightCycler software system. The dynamic range was wide, with five orders of magnitude. A strong linear relationship with a $r^{2}>0.98$ between the fractional cycle number and the log of the starting copy number was demonstrated for the four standard curves. The efficiencies of amplification (Es; mean \pm SD) were $0.87 \pm 0.039$, with $\mathrm{R}^{2}=0.999 \pm 0.001$ for ubiquitin, $0.87 \pm 0.059$ with $\mathrm{R}^{2}=0.991 \pm 0.008$ for GAPDH, $0.53 \pm 0.11$ with $\mathrm{R}^{2}=0.998 \pm 0.002$ for eIF4AII and $0.82 \pm 0.137$ with $\mathrm{R}^{2}=0.995 \pm 0.006$ for $18 \mathrm{~S}$ rRNA. Intra-run variation (expressed as \% molecules) averaged $13.7 \pm 7.5$ for ubiquitin, $13.4 \pm 9.2$ for eIF4AII, $28.8 \pm 13.7$ for $18 \mathrm{~S}$ rRNA and $13.72 \pm 5.0$ for GAPDH.

\section{Quantification}

The unknown initial sample copy numbers were automatically calculated from their Cts, as compared to the respective standard curve, previously created (as described above) and imported by the LightCycler software system. For the LEA-like gene, quantification was performed using a previously determined standard curve (data not shown). The expression levels obtained for the four housekeeping genes during nine stages of embryo development are shown in Fig. 2. All four housekeeping genes showed great variability in transcript number, with an average range fold variation, relative to $\mathrm{T} 0$, of seven fold (Fig. 2). 
Fig. 2 Average \pm SE of transcript copy number of ribosomal 18S (a), ubiquitin (b), GAPDH (c) and eIF-4AII (d) per developmental stage. DAT0 - days after T0 stage of embryo development. Means followed by different letter suffixes are statistically significant different as evaluated by ANOVA for $18 \mathrm{~S}[\mathrm{~F}(8,71)=5.89 ; P<0.001]$, ubiquitin $[\mathrm{F}(8,72)=11.325$; $P<0.001]$, GAPDH $[\mathrm{F}(8,72)=$ 4.18; $P<0.001]$ and eIF-4AII $[\mathrm{F}(8,72)=4.01 ; P=0.001]$ followed by Tukey's HSD
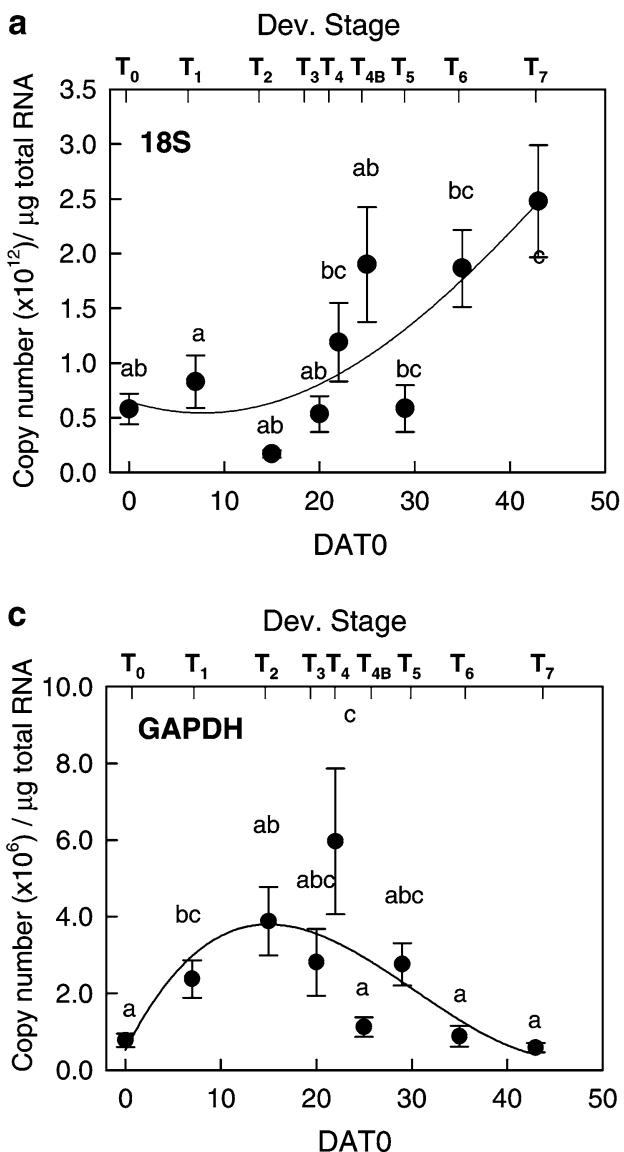
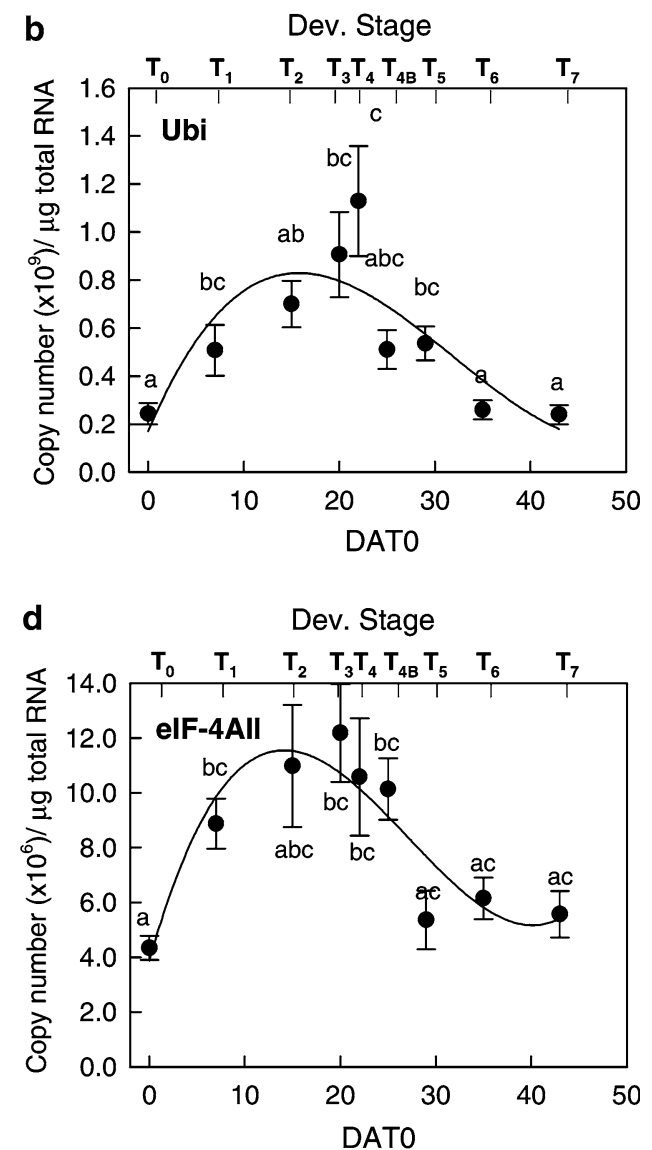

\section{Discussion}

A study of the expression levels of four housekeeping genes in nine stages of zygotic embryo development in maritime pine revealed that none of the genes tested is suitable for normalisation of RNA levels. Ribosomal $18 \mathrm{~S}$ shows an overall increase of expression during embryo development while glyceraldehyde-3-phosphatedehydrogenase, ubiquitin and eukaryotic translation initiation factor eIF4AII revealed a maximum of expression in middle stages of embryogenesis (Fig. 2). These middle stages correspond to the T3-T4B stages, where cotyledon primordia formation, the main differentiation event during embryo development, occurs (Fig. 1). This transition is generally very fast, (3-5 days). It is therefore likely that during these developmental stages, an increase in expression of genes related to cellular division, growth and energy consumption is required to support cellular differentiation and growth. Glyceraldehyde-3-phosphate-dehydrogenase is an abundant glycolytic enzyme and therefore an increase in transcription is consistent with a higher demand of cellular energy associated with growth and cell differentiation. Normalisation to GAPDH was already reported as valid (Wall and Edwards 2002), however in most cases this gene proved to be inappropriate as endogenous control in quantification assays (Schmittgen and
Zakrajsek 2000; Goidin et al. 2001; Kim et al. 2003). A maximum variability of GAPDH of 25 fold has been reported (Dheda et al. 2004), and according to Bustin (2002) for most experimental conditions the use of GAPDH is inappropriate and should be discontinued. Our results support this conclusion.

Ubiquitin is associated with the regulation of protein turnover in a cell by closely targeting specific proteins for degradation. Ubiquitin-mediated proteolysis of cellular proteins is a highly complex, temporally controlled and tightly regulated process which plays important roles in a broad array of cellular processes like cell cycle and division, differentiation and development and biogenesis of organelles, among others (Ciechanover 1998). By regulating protein degradation, cells can quickly eliminate a protein that in turn regulates another function. Most frequently, the ubiquitin tag is used to mark particular proteins for proteolytic elimination, but it can also have nonproteolytic functions (Hochstrasser 2000).

Eukaryotic translation initiation factor $4 \mathrm{~F}$ (eIF4F, eIF4A, and eIF4B) is a protein complex that mediates the recruitment of ribosomes to mRNA. Functions of eIF4A isoforms include delivery of an RNA helicase to the $5^{\prime}$ region of the mRNA (Gingras et al. 1999). These proteins participate in diverse processes apart from translation, including pre-mRNA splicing and ribosome assembly. They are also important cellular factors for regulatory events, in particular during organ maturation 
and cellular growth and differentiation (Aubourg et al. 1999). A high level of variability in expression of the translation initiation factor eIF4B has been recently reported in poplar tissues from different developmental stages (Brunner et al. 2004). We may therefore suggest a putative association between the increase of eIF4AII transcript and the differentiation of cotyledons.

The use of ribosomal RNA has been also recommended as internal standard for mRNA quantification studies because mRNA variations are usually reduced in comparison to rRNA and cannot highly modify the total RNA level (Thellin et al. 1999). In fact, $18 \mathrm{~S}$ ribosomal RNA has been reported as a reliable reference gene for real-time RT-PCR in distinct experimental conditions (Schmittgen and Zakrajsek 2000; Goidin et al. 2001; Kim et al. 2003). However, according to Solanas et al. (2001) there are some concerns regarding the use of rRNA as internal standard due to variations in rRNA expression levels, transcription by different RNA polymerases and possible imbalances in rRNA and mRNA fractions between different samples. Our study demonstrated a great variability in the levels of expression of the $18 \mathrm{~S}$ ribosomal RNA during the different stages of embryo development, with an overall increase in the late stages of embryogenesis. In the final maturation stage, the embryo completes the synthesis of storage materials, undergoes hormonal changes, and expresses new sets of genes to prepare for dormancy and desiccation. The increase of rRNA 18S during these late stages may be due to a higher demand on transcription events.

The expression levels of a LEA-like gene during the nine stages of embryo development are shown in Fig. 3. The LEA-like transcript used in this study had been previously identified in $P$. pinaster (Dubois and Plomiom 2003). LEA proteins are produced in abundance during late embryo development and their expression is linked to the acquisition of desiccation tolerance,

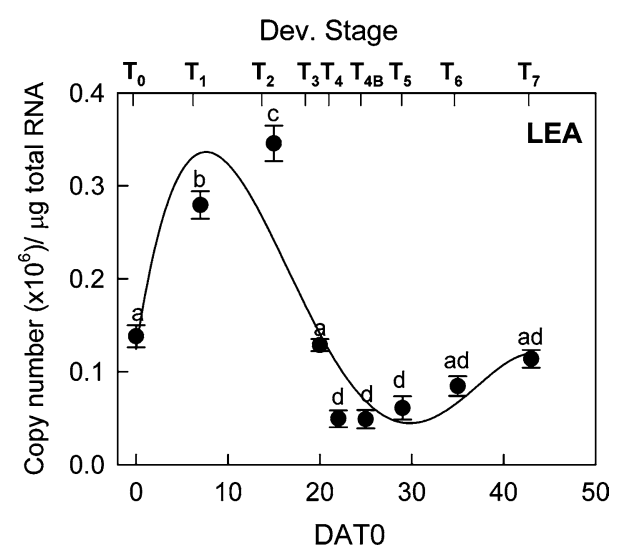

Fig. 3 Average \pm SE of LEA-like transcript copy number per developmental stage. DAT0 - days after T0 stage of embryo development. Means followed by different letter suffixes are statistically significant different as evaluated by ANOVA $[\mathrm{F}(8,18)$ $=75.959 ; P<0.001]$, followed by Tukey's HSD although their function is not yet clear (Wise and Tunnacliffe 2004). Further, many LEA genes are induced by abscisic acid (ABA) and their level of expression tracks endogenous ABA levels (Bray 1997), a phenomenon that has also been observed during conifer embryogenesis (Dong and Dunstan 2000). The experiment with the LEA-like gene of $P$. pinaster was included in this study to demonstrate that our calculation method generates results that are consistent with results gained using other methods to assay gene expression. Our results confirm an increase in expression from middle to late stages of embryo development (T4 to T7), with a peak in expression observed between stages T0 and T2. According to Kapik et al. (1995) this peak in expression corresponds to a peak in ABA abundance observed in early stage embryos of loblolly pine. These authors observed a second peak in ABA abundance late in embryogenesis, during the desiccation phase of seed development. Our embryo samples did not extend into this phase of embryo maturation, hence a single peak is observed in Fig. 3. Our results are also consistent with Northern hybridization analysis of LEA-like and dehydrin-like genes from loblolly pine, where two peaks in gene expression (early-mid development and late, desiccation-phase) corresponded to the two peaks in ABA abundance (data not shown). The early-mid-stage peak in gene expression in loblolly pine corresponds to the peak observed in Fig. 3.

The results obtained for the four housekeeping genes may be partially explained by the fact that housekeeping proteins are not only implicated in the basal cell metabolism but also participate in other functions (Sirover 1999). The tissue used may be for itself a reason of this variation in the levels of expression of the housekeeping genes. Embryogenesis of higher plants is divided conceptually into two distinct phases: early morphogenetic processes that give rise to embryonic cell types, tissues, and organs and late maturation events that allow the fully developed embryo to enter a desiccated and quiescent state (West and Harada 1993; Goldberg et al. 1994). It is therefore reasonable to assume that the level of expression of the genes tested has such a high variability due to these major developmental changes during embryo development.

If the normalisation is performed against total RNA, the controversy of housekeeping genes may be avoided. However, it is normally considered that normalisation to total RNA content is not suitable, due to the difficulties in quantifying small amounts of RNA and due to variations in RT and PCR efficiencies. RiboGreen RNA (Molecular Probes) is a quantitation reagent used for RNA quantification. The RiboGreen quantification assay relies on a proprietary dye that exhibits significant fluorescent enhancement upon binding to nucleic acids and that can be detected using a spectrofluorometer, a fluorescence microplate reader or a filter-based fluorometer (Jones et al. 1998). At high RNA concentrations, quantification made through absorbance at $260 \mathrm{~nm}$ and through the Ribogreen assay are 
comparable (Bustin 2000). However, at the RNA concentrations typically used for real-time RT-PCR, the RiboGreen assay clearly shows less variability than UV absorbance, allowing a more accurate measurement of lower amounts of RNA (Hashimoto et al. 2004). The introduction of standard internal controls to monitor RT and PCR efficiencies would allow a reliable normalisation to total RNA (Bustin 2000).

The use of external calibration curves is normally used for absolute quantification. An external calibration curve using DNA has been shown to be a better model for the quantification of mRNA than the RNA calibration model (Pfaffl and Hageleit 2001). The application of a single, well-constructed standard curve can provide an accurate measurement of transcript copy number (Rutledge and Côté 2003)

Our study has demonstrated a high variability of the four genes tested during embryo development, invalidating their use as internal standards in real-time RTPCR. Nevertheless, these are genes commonly used as housekeeping in a wide range of organisms and experimental conditions. Further studies testing a higher number of housekeeping genes may be necessary to find a suitable one. However this is a time consuming and costly approach that may prove unproductive. In our study we have also observed a high variability in the levels of expression of $\beta$-actin during embryogenesis (data not shown). With this study we have demonstrated that it is absolutely necessary to perform a prior study on the stability of transcript abundance for the genes used as internal controls in the same experimental conditions.

Our results suggest that the combination of a precise method for RNA quantification with internal controls for monitoring RT reaction and PCR efficiency, and with a robust external standard curve can guarantee a reliable absolute quantification of mRNA transcripts in real time RT-PCR. This may assume especial importance in the case of tissues in different developmental stages, where we might expect a high number of genes being up and down regulated.

Acknowledgements This research was supported by Fundação para a Ciência e a Tecnologia (FCT) and the III Framework Program of the EC through grants SFRH/BD/3135/2000 (SG) and SFRH/ $\mathrm{BPD} / 17902 / 2004(\mathrm{CM})$ and through project POCTI/AGR/46283/ 2002. We thank Dr Concepción Ávila (Laboratorio de Bioquímica y Biología Molecular, Facultad de Ciencias-Instituto Andaluz de Biotecnología, Universidad de Málaga, Spain), for providing primer sequence information regarding eIF-4AII gene. Estação Florestal Nacional (EFN) is acknowledged for making plant material available. JC acknowledges support from the National Science Foundation Plant Genome Program, Award No. 0217594.

\section{References}

Aubourg S, Kreis M, Lecharny A (1999) The DEAD box RNA helicases family in Arabidopsis thaliana. Nucleic Acids Res 27:628-636

Barbu V, Dautry F (1989) Northern blot normalization with a $28 \mathrm{~S}$ rRNA oligonucleotide probe. Nucleic Acids Res 17:7115
Bray EA (1997) Plant responses to water deficit. Trends Plant Sci 2:48-54

Brunner AM, Yakovlev IA, Strauss SH (2004) Validating internal controls for quantitative plant gene expression studies. BMC Plant Biol 4:14

Bustin SA (2000) Absolute quantification of mRNA using real-time reverse transcription polymerase chain reaction assays. J Mol Endocrinol 25:169-193

Bustin SA (2002) Quantification of mRNA using real-time reverse transcription PCR (RT-PCR): trends and problems. J Mol Endocrinol 29:23-39

Charrier B, Champion A, Henry Y, Kreis M (2002) Expression profiling of the whole Arabidopsis shaggy-like kinase multigene family by real-time reverse transcriptase-polymerase chain reaction. Plant Physiol 130:577-590

Ciechanover A (1998) The ubiquitin-proteasome pathway: on protein death and cell life. EMBO J 17:7151-7160

Cottrell SE, Distler J, Goodman NS, Mooney SH, Kluth A, Olek A, Schwope I, Tetzner R, Ziebarth H, Berlin K (2004) A realtime PCR assay for DNA-methylation using methylation-specific blockers. Nucleic Acids Res 32:e10

Daram P, Brunner S, Persson BL, Amrhein N, Bucher M (1998) Functional analysis and cell-specific expression of a phosphate transporter from tomato. Planta 206:225-233

Dheda K, Huggett JF, Bustin SA, Johnson MA, Rook G, Zumla A (2004) Validation of housekeeping genes for normalizing RNA expression in real-time PCR. Biotechniques 37:112-119

Dong JZ, Dunstan DI (2000) Molecular biology of somatic embryogenesis in conifers. In: Jain SM, Minocha SC (eds) Molecular biology of woody plants. Kluwer Academic Publishers Amsterdam, pp 51-87

Dubos C, Plomion C (2003) Identification of water-deficit responsive genes in maritime pine (Pinus pinaste Ait.) roots Plant Mol Biol 51:249-262

Eisenberg E, Levanon EY (2003) Human housekeeping genes are compact. Trends Genet 19:362-365

Feroze-Merzoug F, Berquin IM, Dey J, Chen YQ (2002) Peptidylprolyl isomerase A (PPIA) as a preferred internal control over GADPH and $\beta$-Actin in quantitative RNA analysis. Biotechniques 32:776-782

Freeman WM, Walker SJ, Vrana KE (1999) Quantitative RTPCR: pitfalls and potential. Biotechniques 26:112-125

Fronhoffs S, Totzke G, Stier S, Wernert N, Rothe M, Brüning T, Koch B, Sachinidis A, Vetter H, Ko Y (2002) A method for the rapid construction of cRNA standard curves in quantitative real-time reverse transcription polymerase chain reaction. $\mathrm{Mol}$ Cell Probes 16:99-110

Galau GA, Bijaisoradat N, Hughes DW (1987) Accumulation kinetics of cotton late embryogenesis-abundant mRNAs and storage protein mRNAs: coordinate regulation during embryogenesis and the role of abcisic acid. Dev Biol 123:198212

Gingras AC, Raught B, Sonenberg N (1999) eIF4 Initiation factors: effectors of mRNA recruitment to ribosomes and regulators of translation. Annu Rev Biochem 68:913-963

Giulietti A, Overbergh L, Valckx D, Decallonne B, Bouillon R, Mathieu C (2001) An overview of real-time quantitative PCR: applications to quantify cytokine gene expression. Methods 25:386-401

Goidin D, Mamessier A, Staquet MJ, Schmitt D (2001) Ribosomal 18S RNA prevails over glyceraldehydes-3-phosphate dehydrogenase and $\beta$-actin genes as internal standard for quantitative comparison of mRNA levels in invasive and non-invasive human melanoma cell subpopulations. Anal Biochem 295:17-21

Goldberg RB, De Paiva G, Yadegari R (1994) Plant embryogenesis: zygote to seed. Science 266:605-614

Hashimoto JG, Beadles-Bohling AS, Wiren KM (2004) Comparison of RiboGreen ${ }^{\circledR}$ and $18 \mathrm{~S}$ rRNA quantitation for normalizing real-time RT-PCR expression analysis. Biotechniques 36:54-60

Hochstrasser M (2000) Evolution and function of ubiquitin-like protein-conjugation systems. Nat Cell Biol 2:E153 - E157 
Johnson MP, Haupt LM, Griffiths LR (2004) Locked nucleic acid (LNA) single nucleotide polymorphism (SNP) genotype analysis and validation using real-time PCR. Nucleic Acids Res 32: 55

Jones LJ, Yue ST, Cheung CY, Singer VL (1998) RNA quantitation by fluorescence-based solution assay: RiboGreen reagent characterization. Anal Biochem 265:368-374

Kang JJ, Watson RM, Fisher ME, Higuchi R, Gelfand DH, Holland MJ (2000) Transcript quantitation in total yeast cellular RNA using kinetic PCR. Nucleic Acids Res 28:e2

Kapik RH, Dinus RJ, Dean JFD (1995) Abscisic acid and zygotic embryogenesis in Pinus taeda. Tree Physiol 15:485-490

Kim BR, Nam HY, Kim SU, Kim SI, Chang YJ (2003) Normalization of reverse transcription quantitative-PCR with housekeeping genes in rice. Biotechnol Letters 25:1869-1872

Lupberger J, Kreuzer KA, Baskaynak G, Peters UR, le Coutre P, Schmidt CA (2002) Quantitative analysis of beta-actin, beta-2microgobulin and porphobilinogen deaminase mRNA and their comparison as control transcripts for RT-PCR. Mol Cell Probes 16:25-30

Mackay IM, Arden KE, Nitsche A (2002) Real-time PCR in virology. Nucleic Acids Res 30:1292-1305

Mason G, Provero P, Vaira A, Accotto G (2002) Estimating the number of integrations in transformed plants by quantitative real-time PCR. BMC Biotechnol 2:20-30

Paule MR, White RJ (2000) Survey and summary: transcription by RNA polymerases I and III. Nucleic Acids Res 28:1283-1298

Pfaffl MW, Hageleit M (2001) Validities of mRNA quantification using recombinant RNA and recombinant DNA external calibration curves in real-time RT-PCR. Biotechnol Lett 23:275282

Pullman GS, Webb DT (1994) An embryo staging system for comparison of zygotic and somatic embryo development. In: Proceedings of the TAPPI R \&D Division Biological Sciences
Symposium, October 3-6, Minneapolis, MN. Technical Association of the Pulp and Paper Industry Press, Atlanta, GA, pp 31-34

Rutledge RG, Côté C (2003) Mathematics of quantitative kinetic PCR and the application of standard curves. Nucleic Acids Res 31:e93

Schmittgen TD, Zakrajsek BA (2000) Effect on experimental treatment on housekeeping gene expression: validation by realtime, quantitative RT-PCR. J Biochem Biophys Methods 46:69-81

Sirover MA (1999) New insights into an old protein: the functional diversity of mammalian glyceraldehyde-3-phosphate-dehydrogenase. Biochim Biophys Acta 1432:159-184

Solanas M, Moral R, Escrich E (2001) Unsuitability of using ribosomal RNA as loading control for Northern blot analysis related to the imbalance between messenger and ribosomal RNA content in rat mammary tumors. Anal Biochem 288:99102

Thellin O, Zorzi W, Lakaye B, De Borman B, Coumans B, Hennen G, Grisar T, Igout A, Heinen E (1999) Housekeeping genes as internal standards: use and limits. J Biotechnol 75:291-295

Vandesompele J, De Preter K, Pattyn F, Poppe B, Van Roy N, De Paepe A, Speleman F (2002) Accurate normalization of realtime quantitative RT-PCR data by geometric avering of multiple internal control genes. Genome Biol 3:0034.1-0034.11

Wall SJ, Edwards DR (2002) Quantitative reverse transcriptionpolymerase chain reaction (RT-PCR): a comparison of primerdropping, competitive and real-time RT-PCRs. Anal Biochem 300:269-273

West M, Harada JJ (1993) Embryogenesis in higher plants. An overview. Plant Cell 5:1361-1369

Wise MJ, Tunnacliffe A (2004) POPP the question: what do LEA proteins do? Trends Plant Sci 9:13-17 